\title{
THE DETERMINATION OF THE CIRCULATING BLOOD VOLUME IN INFANTS BY THE CARBON MONOXIDE METHOD
}

\author{
By RUSTIN McINTOSH \\ (From the Harriet Lane Home and Department of Pediatrics, the Johns Hopkins \\ University, Baltimore, Maryland)
}

(Received for publication December 3, 1928)

The carbon monoxide method for determination of blood volume has been used with success in experiments on adults, but has to our knowledge not been previously applied to infants. Miller (1) in 1910 employed the procedure as refined by Zuntz and Plesch (2) in studying a group of thirty children ranging from 6 to 16 years of age, but no reports of studies in younger individuals are available.

The principle of this method was first advocated by Gréhant and Quinquaud (3), and was first applied to the study of blood volume in man by Haldane and Lorrain Smith (4). Improvements in the form of application have been contributed by a number of workers (5), particularly by Salvesen (6) and by Harrop and his associates (7). An accurately measured quantity of carbon monoxide gas is delivered into a breathing apparatus, from which it is absorbed rapidly from the respired air. The time required for maximal absorption, and the conditions under which absorption is accelerated, have been carefully determined by Harrop. After a suitable interval has elapsed for the establishment of equilibrium between the gas in the circulating blood and the respired air, and for complete mixing of the blood, a sample of the latter is withdrawn from a vein and analyzed for carbon monoxide content by an adaptation of the method of Van Slyke and Robscheit-Robbins (8). When the proper corrections have been applied, the calculation of the circulating blood is then simplified to the following equation:

$$
\text { Circulating blocd volume }=\frac{\text { Quantity of gas absorbed } \times 100}{\text { Percentage of gas in the blood }}
$$


TECHNIQUE

Pure carbon monoxide is generated from a mixture of formic acid and sulfuric acid with the application of heat, is washed in a trap containing potassium hydroxide solution to remove traces of free acid, and stored in bottles over a mixture of equal parts of glycerine and saturated solution of sodium chloride, a mixture chosen by Harington and Van Slyke (9) for its low vapor tension and low gas solubility. Samples of the stock of gas are analyzed in the Harington-Van Slyke

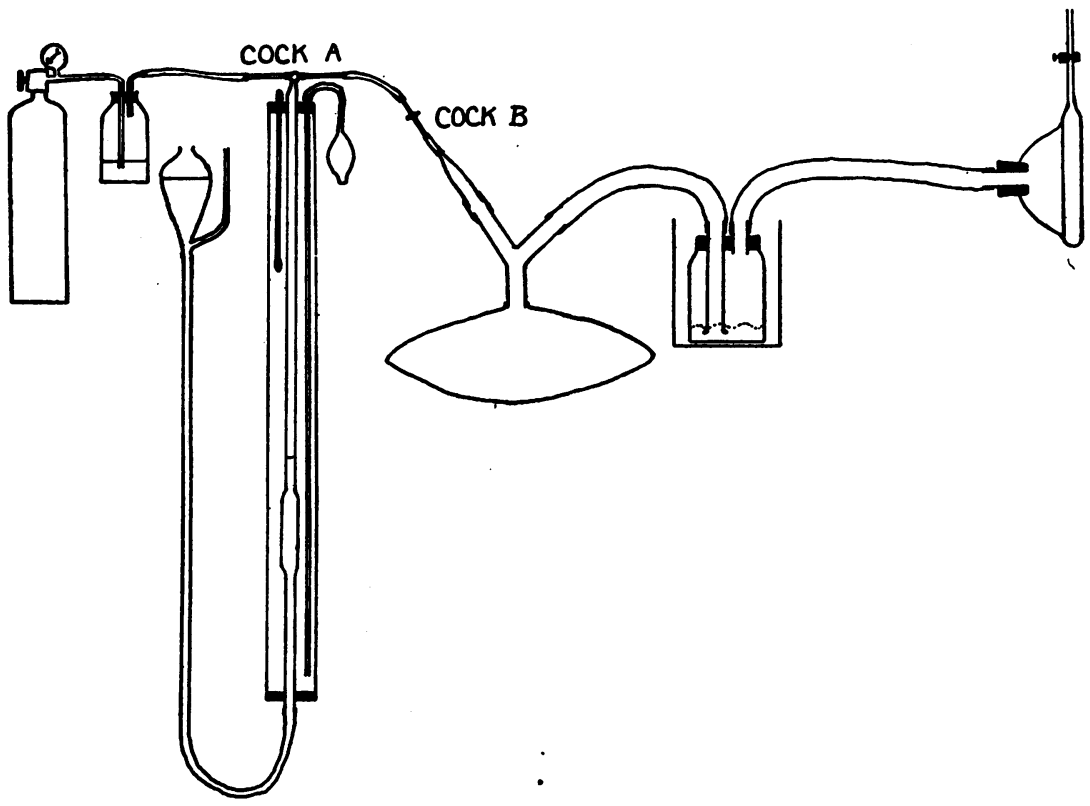

Fig. 1. Diagram of Apparatus for Administration of a Measured Amount of CARbon Monoxide

manometric apparatus to determine the purity factor, the results of parallel determinations agreeing usually within 0.2 per cent. In clinical tests the gas is measured from a specially constructed buret, fitted with a three-way capillary stopcock (cock $A$ in fig. 1) at the top, and provided with a water jacket, thermometer, and levelling bulb filled with glycerol-salt mixture, adapted for delivering any quantity of gas up to about $27 \mathrm{cc}$. with an error of measurement of probably less than $0.05 \mathrm{cc}$. 
The breathing apparatus consists of a face-mask, a soda-lime jar, and a rubber balloon, connected by rubber tubing. The face-mask is made of a half-ovoid of transparent celluloid fitted with a rubber pneumatic cushion about the rim and a tight-fitting one-hole rubber stopper piercing the apex of the dome. The mask is connected to the soda-lime jar by a piece of rubber tubing of $17 \mathrm{~mm}$. bore. The sodalime jar is made from a pint mason jar and two test tubes, fixed in place with plaster of paris and sealed with sealing wax. To facilitate changing the soda-lime the jar has been broken along a circle about $2 \mathrm{~cm}$. from the bottom, so that it may be taken apart, and sealed up with soap and adhesive tape, reinforced with two strong wide rubber bands cut from an inner tube. No. 4 mesh soda-lime is used, held in place by two circular pieces of fine wire gauze, one at the bottom and one at the top of the jar, and is changed after every one or two determinations. During tests on patients the soda-lime jar is immersed in a jacket containing ice water to lower the water vapor tension of the rebreathed air and diminish the discomfort of breathing warm air, and to control leakage. A piece of rubber tubing of $17 \mathrm{~mm}$. bore connects the soda-lime jar with a large-bore glass Y-tube, to one shank of which is attached a football bladder, and to the other, suitable rubber and glass tubing leading to a one-way stop-cock (cock $B$ ). All connections are wired or sealed with sealing-wax.

In testing for leaks, the buret was connected to the breathing apparatus by a piece of small-bore rubber tubing joining cocks $A$ and $B$, and the face-mask was tied firmly against a greased porcelain plate so that the pneumatic cushion was in apposition throughout its circumference. A positive pressure of about $30 \mathrm{~cm}$. of glycerol-salt solution was then exerted on the air in the gas buret, and with the levelling bulb clamped in this position the loss of gas pressure was noted. When the leakage amounted to a pressure change of less than $0.15 \mathrm{~mm}$. of glycerol-salt per minute, the apparatus was considered suitable for use in clinical tests. During actual use, leakage through the division in the soda-lime jar is prevented by immersing it in water to a depth of about $10 \mathrm{~cm}$.; since the balloon is never allowed to become sufficiently distended, during a test, to put the rubber on the stretch, it is not possible for the air contained in the breathing system to overcome the critical pressure exerted by this protective water-jacket. 
Of course, it has not been possible to make control tests of leakage around the edges of the mask when applied to a patient, but this source of error is minimized as far as possible by the liberal application of petrolatum to the pneumatic cushion, by the constant application of firm manual pressure to the mask, and by careful attention to this part of the apparatus throughout the breathing period. In preliminary tests with the mask, which are always made with each patient before carbon monoxide is let into the system, different positions of the mask are tried out until a good apposition is obtained, which can then be held until the end of the experiment.

Before a determination, the gas buret is filled to a convenient level with carbon monoxide and the levelling bulb is clamped in a position causing the contents of the buret to be at a pressure less than atmospheric; at least fifteen minutes are allowed for drainage of solution from the walls of the buret before the pressure is brought to atmospheric and the volume, temperature, and barometric pressure recorded. A small oxygen tank fitted with a water trap and pressure gauge is then connected to the gas buret by one arm of cock $A$. The other arm is connected to cock $B$. The contents of the balloon are expelled, and the tube connecting the face-mask and the soda-lime jar clamped off. With cock $A$ turned so as to close the buret but allow communication between the oxygen tank and the breathing apparatus, oxygen is run into the balloon in an amount estimated to be about four or five times the tidal air of the patient. A sample of blood, usually $7 \mathrm{cc}$. to permit duplicate determinations, is now drawn from the patient under paraffin oil and delivered under oil into a bottle containing oxalate. Even in small infants a definite quantity of gas absorbable by Winkler's solution is usually detectable in these preliminary samples, and is probably either evidence of the known contamination of urban atmosphere with carbon monoxide derived from illuminating gas, automobile exhaust gas, and from other sources, or represents a systematic error of the method. The mask, with the pneumatic cushion well greased, is then applied to the patient's face, the clamp removed from the tube connecting the mask with the soda-lime jar, and the patient allowed to breathe into the apparatus for a short period during which the position of the mask is adjusted for the best approximation. With the levelling bulb of the gas buret raised to the 
level of cock $A$, and with cock $B$ open, carbon monoxide is delivered into the breathing apparatus in an amount estimated to produce a final concentration in the patient's blood of approximately 3 volumes per cent. Cock $A$ is then turned so that the buret is closed but the connection between the oxygen tank and the breathing apparatus open, and a slow stream of oxygen allowed to run in at a rate which will keep the balloon nearly empty at full inspiration. A breathing period of ten minutes or more is allowed, at the end of which a second sample of blood is withdrawn under oil while the mask is still in place.

TABLE 1

Factors by which $P_{\mathrm{CO}}$ is multiplied to calculate volume per cent of $\mathrm{CO}$

\begin{tabular}{c|c} 
Temperature & $\begin{array}{c}\text { Factor when } P_{\text {co }} \text { is measured with gas at } 0.5 \text { cc. } \\
\text { volume }\end{array}$ \\
\hline${ }^{\circ} \mathrm{C}$. & \\
20 & 0.02059 \\
21 & 0.02650 \\
22 & 0.02042 \\
23 & 0.02035 \\
24 & 0.02028 \\
25 & 0.02021 \\
26 & 0.02014 \\
27 & 0.02007 \\
28 & 0.02000 \\
29 & 0.01993 \\
30 & 0.01986 \\
\hline
\end{tabular}

In the equation of Van Slyke and Neill, $a=0.5$

$$
\begin{aligned}
S & =15.0 \\
i & =1.00 \\
\text { cc. sample } & =3.0
\end{aligned}
$$

The oxygen stream is then turned off, $\operatorname{cock} B$ closed, the mask clamped off and removed. The analysis of the blood samples for carbon monoxide is made in duplicate on $3 \mathrm{cc}$. portions by an adaptation of the method of Van Slyke and Robscheit-Robbins (8), and the percentage of added carbon monoxide is then determined by subtraction of the average figures. The factors used to convert differential pressure readings to volumes per cent of gas are calculated from the equation of Van Slyke and Neill (10) and are given in table 1.

The air resistance in the apparatus so designed is not great, and is 
compatible with comfortable rebreathing during periods as long as twenty minutes when tests are made on older children whose confidence can be gained. Most of the infants, naturally, have fretted or cried during the greater part of the breathing period, though a few have slept throughout. Since the rapidity with which the gas is absorbed depends to a large extent on the rate of pulmonary ventilation, it has been customary to prolong the breathing period an additional five or ten minutes in the case of infants who remain quiet. With vigorous crying some of the infants become slightly cyanotic, but not more so than is commonly seen under ordinary circumstances. In a few instances where toxic infants were being studied the color improved as a result of the administration of oxygen incidental to the test. We have observed no harmful effects attributable either to the carbon monoxide specifically or to the test in general, and the disadvantages to the patient are apparently confined to the loss of about $15 \mathrm{cc}$. of blood and the discomfort of the two venapunctures and temporary restriction of activity. The gas does not appear to be retained long; in one patient in whom the test was repeated after 46 hours, the concentration of carbon monoxide had fallen from a level of 3.75 volumes per cent at the termination of the first test to 0.11 volumes per cent at the commencement of the second. Since carboxyhemoglobin does not participate in the oxygen-carrying function of blood, it is obvious that the carbon monoxide method of blood volume determination should not be applied to patients with severe anemia.

\section{DISCUSSION OF ERRORS}

1. The denominator in equation $I$. The analytical error in duplicate determinations by the foregoing technique depends very little on the amount of carbon monoxide present in the sample of blood. In a series of 13 duplicate analyses of samples drawn before any administration of carbon monoxide, the average deviation from the mean in the different pairs of determinations, expressed in volumes per cent of the gas at N.T.P., was. $0.014 \pm 0.012^{1}$ volumes per cent. In another series of 30 duplicate analyses after carbon monoxide had been given for blood volume determinations, where the final concentration

1 The second figure indicates the standard deviation. 
was somewhere between 1.4 and 5.3 volumes per cent, the error expressed in the same way was $0.025 \pm 0.018$. Thus, the analytical error may be expressed as follows:

$$
\begin{aligned}
\text { Analytical Error } & =\frac{\text { Sum of absolute errors for both samples } \times 100}{\text { Difference of the mean of the two samples }} \\
& =\frac{(0.014 \pm 0.012+0.025 \pm 0.018) \times 100}{3.00}
\end{aligned}
$$

or approximately 2.3 per cent for an elevation of the carbon monoxide level of 3.00 volumes per cent. For a larger amount of gas administered, the error is correspondingly diminished.

2. The numerator in equation $I$. The measurement of the quantity of carbon monoxide absorbed by the patient involves three sources of error: (a) determination of the amount of gas injected into the breathing system; (b) leakage from the system during the breathing period; and $(c)$ determination of the residue of carbon monoxide remaining in the apparatus at the end of the breathing period.

As a matter of convenience precautions are taken to prepare fairly pure carbon monoxide gas by washing out the generator and the storage bottles several times before the final collection of gas for stock. The advantage of making the tests for purity in the HaringtonVan Slyke manometric apparatus is twofold: in the first place, satisfactory checks are readily obtained; and in the second place, the use of Winkler's solution for the final absorption of the gas, by an identical procedure to that used in blood analysis, offers a better basis for comparison of results than other methods such as combustion. As was stated previously, the results of duplicate determinations usually agree within 0.2 per cent. The measurement of the gas delivered into the breathing apparatus from the gas buret is held to be accurate to $0.05 \mathrm{cc}$., including herein the errors associated with barometer and thermometer readings, so that for a volume of $20 \mathrm{cc}$. at room temperature the error from this source amounts to less than 0.25 per cent.

A preliminary test was made to determine the rate of diffusion of carbon monoxide through rubber. Under a positive pressure of about $30 \mathrm{~cm}$. of glycerol-salt solution, the pure gas passes through the wall 
of an ordinary piece of thin-walled rubber tubing at a rate of approximately $0.0003 \mathrm{cc}$. per square centimeter of surface per hour. At the low partial pressure of $\mathrm{CO}$ in the apparatus during a blood volume determination, this leakage does not introduce an appreciable error.

The control of leaks in the breathing apparatus has been dealt with to some extent previously. After every two or three determinations the entire apparatus is tested by immersion in water and exertion of positive pressure on the balloon. It is always possible by the use of sufficient force to cause bubbles to appear around the break in the

TABLE 2

Duplicate determinations in individual patients with short time intervals

\begin{tabular}{|c|c|c|c|c|c|c|c|}
\hline Patient & . & Date & Weight & $\begin{array}{c}\text { Blood } \\
\text { volume }\end{array}$ & $\begin{array}{l}\text { Blood } \\
\text { volume }\end{array}$ & $\begin{array}{l}\text { Plasma } \\
\text { volume }\end{array}$ & $\begin{array}{l}\text { Plasma } \\
\text { volume }\end{array}$ \\
\hline \multirow{3}{*}{ A. H. } & & & kgm. & $c c$. & $\begin{array}{c}c c . \text { per } \\
\text { kgm. }\end{array}$ & $c c$. & $\begin{array}{c}\text { cc. per } \\
\text { kgm. }\end{array}$ \\
\hline & & April 9, 1928 & 7.29 & 620 & 85.0 & 370 & 50.8 \\
\hline & & April 27, 1928 & 7.58 & 560 & 75.2 & 290 & 38.6 \\
\hline \multirow{2}{*}{ M. C. } & & May 17,1928 & 8.30 & 600 & 72.3 & 337 & 40.6 \\
\hline & & May 19, 1928 & 8.27 & 565 & 68.3 & 323 & 39.1 \\
\hline \multirow{2}{*}{ M. A. } & & September 4, 1928 & 4.72 & 320 & 67.8 & 196 & 41.5 \\
\hline & & September 14, 1928 & 4.81 & 320 & 66.5 & 185 & 38.5 \\
\hline \multirow{2}{*}{ F. B.. } & & September 10, 1928 & 4.30 & 270 & 62.8 & 164 & 38.1 \\
\hline & & September 19, 1928 & 4.42 & 300 & 67.9 & 198 & 44.8 \\
\hline \multirow{2}{*}{ L. G. . } & & September 15, 1928 & 6.10 & 355 & 58.2 & 218 & 35.7 \\
\hline & & September 26, 1928 & 6.38 & 355 & 55.6 & 199 & 31.2 \\
\hline
\end{tabular}

soda-lime jar, but, as was also stated above, this part of the apparatus is sealed off by a water trap during tests on patients. The most obvious source of error in respect to leakage is, of course, the face-mask, to the careful approximation of which the greatest attention is given during the entire breathing period. Experimental control of this factor by duplicate determinations of blood volume on individual patients predicates a basic assumption of the constancy of the blood volume which, in the light of present knowledge, must be considered still an open question. Five such duplicate tests, performed with intervals of 
from 2 to 18 days, are listed in table 2 and suggest, at any rate, that the error here is at least not large.

The quantity of carbon monoxide absorbed by the patient is the difference between the amount injected into the breathing apparatus and the amount remaining in it at the end of the breathing period. Such residual amounts are small but detectable, and while in our determinations they have not been found to be sufficiently great to influence the final figure for total blood volume, as calculated without taking them into account, by more than 2.7 per cent, and therefore within the total error of the method, it is possible that one may be able at some time to show that in the presence of acidosis they will be large enough to be important, as suggested by the work of Stadie (11) on the absorption coefficient of blood for carbon monoxide under varying hydrogen-ion concentrations. Salvesen (6) in determining the blood volume of rabbits by the carbon monoxide method, had made use of sheep's blood as a reagent for absorbing the residual gas, determining the absorption coefficient of this particular blood by exposing samples of it to varying atmospheric concentrations of carbon monoxide. In our first attempts to utilize this method, with samples of human blood as the absorbing reagent, we were unable to detect the presence of any residual carbon monoxide by simple exposure of the residual air in the apparatus to the blood used. However, since it has been shown that the dissociation curve of carbon monoxide hemoglobin exposed to an atmosphere containing both oxygen and $\mathrm{CO}$ is expressed by the equation

$$
\frac{\mathrm{HbCO}}{\mathrm{HbO}_{2}}=K \times \frac{(\mathrm{CO} \text { percentage in air })}{\left(\mathrm{O}_{2} \text { percentage in air }\right)}
$$

it seemed likely that this analytical method might be considerably refined by removing the oxygen from the residual air before exposing it to the blood used for absorption of the carbon monoxide.

The method used is similar to that employed by Whipple and his associates (12), except that it requires no special apparatus other than two or three Haldane gas sampling tubes. The volume of residual air is first determined by adding together the contents of the balloon, of the breathing apparatus (exclusive of the balloon) from $\operatorname{cock} B$ to the pneumatic cushion of the mask, and of the "dead space" of the 
patient included in the capacity of the respiratory system. The contents of the balloon are measured by drawing them into calibrated sampling tubes. A figure for the capacity of the rest of the breathing apparatus may be obtained by filling it with water; and since this amount did not change significantly from one determination to another in spite of the fact that no particular effort was made to duplicate precisely the quantity of soda-lime used, the same figure, $490 \mathrm{cc}$, was used for all determinations after the first three. The dead space may be estimated roughly from considerations of the patient's age and size; and since the proportion which this part of the total residual air volume bears to the whole is always small, large errors here do not influence the final result. A 50-cc. portion of the residual air, conveniently stored in the sampling tubes, is delivered into the HaringtonVan Slyke pipet. Five cubic centimeters of alkaline pyrogallate solution are then run in and shaken up with the gas for five minutes, and a pressure reading taken with the meniscus at the $50-\mathrm{cc}$. mark. The reagent is then ejected through the lower chamber and a second 5-cc. portion admitted and similarly shaken to insure complete removal of oxygen, as shown by pressure readings. Several 5-cc. portions of glycerol-salt solution are now used successively to wash out the apparatus until practically no staining of the wash solution is obtained. The last washings are ejected through the lower outlet, and the gas in the pipet, now comprising mainly nitrogen and a small proportion of carbon monoxide, are subjected to a pressure slightly less than atmospheric. Two cubic centimeters of glycerol-salt solution are run into the cup, and through this an accurately-measured 3-cc. portion of human blood is delivered into the apparatus, about $1 \mathrm{cc}$. of the glycerol-salt solution serving to wash the last portion through the capillary, which is then sealed with mercury. This blood is drawn from an arm vein with stasis; to insure optimal conditions for carbon monoxide absorption, and is delivered under paraffin oil into a bottle containing oxalate. The mercury in the pipet is now set at the 50-cc. mark so that the blood can be agitated gently with the mechanical shaking device without troublesome foaming. At the end of ten minutes, which under these conditions are taken to be sufficient for nearly complete absorption of the carbon monoxide, $1 \mathrm{cc}$. of glycerol-salt solution is introduced into the cup and covered with $1 \mathrm{cc}$. 
of paraffin oil. The gas in the pipet is brought to a pressure greater than atmospheric and allowed to escape slowly through the upper cock. With the expulsion of the last few bubbles of gas, a small amount of blood escapes through the capillary and mixes with the glycerol-salt solution but does not rise above the layer of oil; in this way its reintroduction into the pipet without loss is facilitated, and its dilution with this small quantity of glycerol-salt solution does not complicate the analysis. The paraffin oil is now removed and $13 \mathrm{cc}$. of ferricyanide . reagent, from which the dissolved gases have already been removed, are delivered into the cup in two portions, $12 \mathrm{cc}$. being allowed to flow into the pipet, the last cubic centimeter being discarded after the capillary has been sealed. The blood sample is now analyzed for carbon monoxide content in the usual way, no special correction being in this case necessary to take into account the increase in the total quantity of fluid by the addition of $1 \mathrm{cc}$. or less of glycerol-salt solution during the procedure as described. In order to determine the quantity of carbon monoxide derived from the portion of residual air with which the blood has been shaken, it is necessary to make control determinations on samples of the blood without exposure to residual air, after which the percentage of added carbon monoxide is found by subtraction. Since the measurements of the total volume of residual air and of the $50 \mathrm{cc}$. sample analyzed are both carried out under approximately equal conditions of temperature and barometric pressure, it is not necessary to reduce these figures to $0^{\circ} \mathrm{C}$. and $760 \mathrm{~mm}$. The amount of unabsorbed carbon monoxide recovered by this method of analysis is expressed by the following equation:

$$
\text { CO in cc. at N.T.P. }=\frac{\text { Total residual air } \times 3 \times \Delta \text { CO per cent in blood }}{50 \times 100}
$$

This quantity is to be subtracted from the measured volume at N.T.P. of carbon monoxide originally injected into the breathing apparatus for calculation of the total blood volume by equation I.

The magnitude of this correction and its effect on the final result in six determinations is expressed in table 3 . In many other determinations it has been disregarded, since it is of approximately the same size as the analytical errors in the determination of the increase in carbon monoxide content of the patient's blood, and also since it is 
always in the same direction in that disregarding the correction causes a false high blood volume figure. In comparative determinations on the same patient this is relatively unimportant.

Chang and Harrop (7) found that in the case of adults at rest and breathing quietly, practically complete absorption of the carbon monoxide injected into the breathing apparatus had taken place after 15 minutes of rebreathing. It seemed probable that this interval

TABLE 3

Absorption of carbon monoxide as determined by analysis of residual air

\begin{tabular}{|c|c|c|c|}
\hline Patient & $\begin{array}{l}\text { CO measured } \\
\text { from buret }\end{array}$ & $\begin{array}{l}\text { Unabsorbed CO } \\
\text { by analysis }\end{array}$ & $\begin{array}{l}\text { Per cent CO } \\
\text { absorbed }\end{array}$ \\
\hline & cc. at N.T.P. & cc. at N.T.P. & per cent \\
\hline S. F. & 11.450 & 0.422 & 96.31 \\
\hline J.L.... & 21.340 & 0.536 & 97.49 \\
\hline$\ldots \ldots \ldots$ & 12.925 & 0.258 & 98.00 \\
\hline M. S... & 14.945 & 0.100 & 99.34 \\
\hline L. G....... & 14.170 & 0.071 & 99.50 \\
\hline 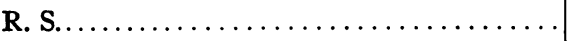 & 19.845 & 0.035 & 99.82 \\
\hline
\end{tabular}

TABLE 4

Control of time required for absorption of $\mathrm{CO}$

Blood carbon monoxide content

\begin{tabular}{|c|c|c|c|c|}
\hline & At start & $\begin{array}{l}\text { After } \\
5 \text { minutes }\end{array}$ & $\begin{array}{l}\text { After } \\
10 \text { minutes }\end{array}$ & $\begin{array}{l}\text { After } \\
15 \text { minutes }\end{array}$ \\
\hline & $\begin{array}{l}\text { volumes } \\
\text { per cent }\end{array}$ & $\begin{array}{l}\text { volumes } \\
\text { per cent }\end{array}$ & $\begin{array}{l}\text { volumes } \\
\text { per cent }\end{array}$ & $\begin{array}{l}\text { volumes } \\
\text { per cent }\end{array}$ \\
\hline A. B. $\ldots \ldots \ldots \ldots \ldots \ldots \ldots \ldots \ldots \ldots \ldots \ldots \ldots$ & 0.077 & $\bullet$ & 3.43 & 3.30 \\
\hline C. $\mathbf{L} \ldots \ldots \ldots \ldots \ldots \ldots \ldots \ldots \ldots \ldots$ & 0.081 & 2.88 & 2.89 & \\
\hline 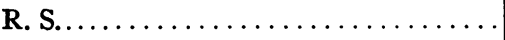 & 0.066 & 4.15 & 4.22 & \\
\hline L. S. $\ldots \ldots \ldots \ldots \ldots \ldots \ldots \ldots \ldots \ldots \ldots \ldots \ldots$ & 0.077 & 5.12 & 5.27 & \\
\hline
\end{tabular}

might well be shorter in the case of infants crying vigorously, and the choice of a ten minute breathing period in our technique is based on a small number of control observations which bore out this supposition, and which are given in table 4. This series has not been enlarged on account of the undesirability of removing additional blood; but the results in patient R. S., where this control was supplemented by analysis of the residual air for unabsorbed carbon monoxide, show that the ten minute period is, in all probability, adequate. This 
patient was suffering from tuberculous meningitis, and during the rebreathing period remained on the whole more quiet than the average patient.

In order to compare the results of determinations of blood volume by the carbon monoxide method with those obtained with the dye method, simultaneous tests were performed on ten patients using both methods in the following way. A preliminary control experiment was made to determine whether the addition of brilliant vital red, the dye used, to human blood would interfere with subsequent absorption of carbon monoxide. Ten cubic centimeters of oxalated human blood were placed in each of two beakers of equal size, and to one sample was added $0.05 \mathrm{cc}$. of physiological salt solution, and to the other $0.05 \mathrm{cc}$.

TABLE 5

Influence of presence of brilliant vital red in blood on absorption of $\mathrm{CO}$

\begin{tabular}{|c|c|c|c|c|c|}
\hline \multirow{2}{*}{$\begin{array}{l}\text { Experiment } \\
\text { number }\end{array}$} & \multicolumn{2}{|c|}{$\begin{array}{l}\text { CO content of control blood } \\
\text { (saline added) }\end{array}$} & \multicolumn{2}{|c|}{$\begin{array}{c}\text { CO content of test blood } \\
\text { (dye added) }\end{array}$} & \multirow{2}{*}{$\begin{array}{c}\text { Difference } \\
\text { (control-dye) }\end{array}$} \\
\hline & $\begin{array}{l}\text { Duplicate } \\
\text { analyses }\end{array}$ & Average & $\begin{array}{l}\text { Duplicate } \\
\text { analyses }\end{array}$ & Average & \\
\hline \multirow[b]{2}{*}{1} & volumes per cent & volumes per cent & volumes per cent & volumes per cent & volumes per cent \\
\hline & $\begin{array}{l}1.027 \\
1.051\end{array}$ & 1.04 & $\begin{array}{l}0.924 \\
0.923\end{array}$ & 0.92 & 0.12 \\
\hline \multirow{2}{*}{2} & 3.776 & & 3.518 & & \\
\hline & 3.742 & 3.76 & 3.531 & 3.52 & 0.24 \\
\hline
\end{tabular}

of a 1 per cent solution of the dye in order to give it a final concentration approximately the same as that effected by the use of the dye in clinical tests. Both beakers were then placed in a vacuum desiccator equidistant from the inlet tube, and with the desiccator lid in place, but not tightly sealed, approximately $100 \mathrm{cc}$. of carbon monoxide gas were slowly admitted, displacing some of the contained air. The lid was then sealed and the desiccator gently agitated for $15 \mathrm{~min}$ utes to permit the gases to attain equilibrium with the blood samples. On removal of the lid, a layer of paraffin oil, one or two centimeters deep, was added to the contents of each beaker, and the two samples were then analyzed for carbon monoxide content. The results, shown in table 5, agreed within the error of the method, we believe; at any 
rate, the error occurred in a direction which would have given, if anything, an abnormally high blood volume by the carbon monoxide method.

In the experiments with patients tabulated in table 6 , the dye method of Keith, Rowntree, and Geraghty (13) was used, slightly modified to suit the conditions of work with infants. Either 1.00

TABLE 6

Comparison of $\mathrm{CO}$ method and dye method in simultaneous blood volume determinations in 10 patients

\begin{tabular}{|c|c|c|c|c|c|c|c|c|}
\hline \multirow[t]{2}{*}{ Patients } & \multirow{2}{*}{ 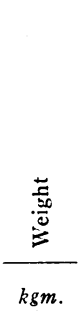 } & $\frac{8}{4}$ & 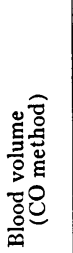 & 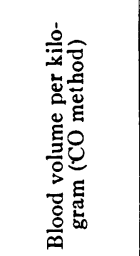 & 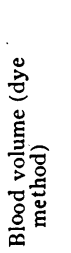 & 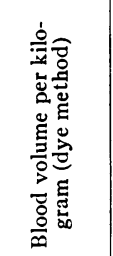 & 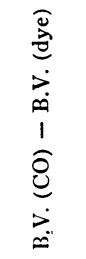 & 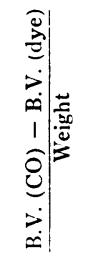 \\
\hline & & months & $c c$. & cc. per kgm. & $c c$ & $\begin{array}{c}c c . p e r \\
k g m .\end{array}$ & $c c$. & $\begin{array}{c}c c . p e r \\
k g m\end{array}$ \\
\hline L. S... & 3.53 & 12 & 275 & 77.9 & 595 & 168.6 & -320 & -90.7 \\
\hline F. B.. & 4.42 & 2 & 300 & 67.9 & 400 & 90.5 & -100 & -22.6 \\
\hline R. W.. & 5.68 & 7 & 445 & 78.3 & 520 & 91.5 & -75 & -13.2 \\
\hline S. E.. & 6.72 & 5 & 410 & 61.0 & 720 & 107.1 & -310 & -46.1 \\
\hline J. L. & 6.75 & 12 & 500 & 74.1 & 475 & 70.4 & +25 & +3.7 \\
\hline D. B.. & 6.87 & 8 & 440 & 64.1 & 500 & 72.8 & -60 & -8.7 \\
\hline W. P.. & 6.90 & 15 & 455 & 66.0 & 845 & 122.5 & -390 & -56.5 \\
\hline R. S.. & 7.47 & 11 & 500 & 66.9 & 550 & 73.6 & -50 & -6.7 \\
\hline C. L.. & 7.80 & 17 & 605 & 77.6 & 455 & 58.3 & +150 & +19.3 \\
\hline J. J... & 8.22 & 21 & 655 & 79.6 & 635 & 77.2 & +20 & +2.4 \\
\hline \multicolumn{4}{|c|}{ Arithmetical mean. } & $71 \pm 2$ & & $93 \pm 10$ & & \\
\hline \multicolumn{4}{|c|}{ Standard deviation. } & $6.6 \pm 1.5$ & & $31 \pm 7$ & & \\
\hline \multicolumn{4}{|c|}{ Coefficient of variation $\ldots \ldots \ldots \ldots \ldots \ldots$} & $9 \pm 2$ & & $33 \pm 7$ & & \\
\hline
\end{tabular}

1.50 or $2.00 \mathrm{cc}$. of a 1 per cent solution of brilliant vital red, diluted to approximately $10 \mathrm{cc}$. with physiological salt solution, was injected, depending on the size of the patient. The same graduated $2 \mathrm{cc}$. pipet was used to measure the dye to be injected and to make up the standard dilution of dye for use in the colorimeter. For the first sample of blood, $10 \mathrm{cc}$. were removed, of which $4 \mathrm{cc}$. were oxalated under oil 
for a single determination of the carbon monoxide content and for hematocrit tests, the rest being allowed to clot in a centrifuge tube for control of the dye method. The dye was then injected, and four or five minutes later the second sample of blood was drawn, 5 or $6 \mathrm{cc}$. in amount, and either oxalated or allowed to clot in a centrifuge tube. A measured amount of carbon monoxide gas was then administered according to the technique outlined previously, and at the end of the usual breathing period 7 or $8 \mathrm{cc}$. of blood were removed and oxalated under oil. In calculating the total blood volume for comparison with the two methods, the figures were corrected by the addition of the amount of blood previously withdrawn. The disagreement between the results of the two methods was often pronounced, and was neither of constant magnitude nor of uniform direction. In seven out of ten such determinations the value of total blood volume expressed in cubic centimeters per kilogram of body weight was higher with the dye method than when the carbon monoxide method was used, and the average of all the determinations with the dye method was $93 \mathrm{cc}$. per kilogram; with the carbon monoxide method, $71 \mathrm{cc}$. per kilogram. The largest discrepancy between the two methods occurred in one patient in whom the blood volume as determined by the dye method exceeded that obtained by the gas method by $320 \mathrm{cc}$., or $91 \mathrm{cc}$. per kilogram; while, in the other direction, the dye method in another patient gave a result that was lower by $150 \mathrm{cc}$. or $19 \mathrm{cc}$. per kilogram than the value given by the carbon monoxide method. If, as has been suggested by previous workers with both methods, the body weight is in any sense a criterion for the expected blood volume, it is clear from these figures that the carbon monoxide is in our hands the more reliable. Perhaps the obvious conclusion one might wish to draw is that our technique with the dye method is faulty, but we are not convinced that this is a complete explanation of the discrepancy. Whipple and his associates (14) in a comparison of the dye, carbon monoxide, and the exsanguination methods for determining total blood volume in dogs, likewise found discrepancies of similar magnitude and direction. In all but one of fourteen dogs the value of total blood volume expressed in cubic centimeters per kilogram of body weight was higher with the dye method than when the carbon monoxide method was used, and the average of all the determinations 
for the dye method was 103.9 cc. per kilogram; for the carbon monoxide method, $86.9 \mathrm{cc}$. per kilogram. It is not within the scope of this paper to discuss the theoretical aspects of the application of these different methods, and we do not at the moment contend that the carbon monoxide method as described here eludes all the theoretical pitfalls of clinical determination of the total blood volume; at the same time, it has in our hands exhibited a closer correlation between blood volume and body weight, as expressed in the coefficient of variation, than have determinations made by the dye method, and there is considerable experimental evidence in the literature that the true blood volume follows body weight in health fairly closely, provided suitable allowances are made for conditions of obesity or severe undernutrition.

\section{REVIEW OF PREVIOUS WORK IN BLOOD VOLUME OF INFANTS}

In this discussion we shall not include the question of the blood volume of newly born infants, since our material does not cover this age group. The investigations of Lucas and Dearing (15) are unique in this field.

The authors just mentioned, in a series of 30 estimations made on 11 nearly normal infants varying in age from two weeks to a year, found an average quantity of $110 \mathrm{cc}$. of blood per kilogram of body weight, as determined by the dye method. Individual patients, though their blood volume might deviate considerably from the average figure when calculated with relation to body weight, nevertheless tended to maintain a fairly constant ratio over a period of as long as two months, which was the maximum interval covered by the duplicate determinations. According to these authors, the ratio of blood volume to body weight is more constant than the ratio plasma volume to body weight. We have calculated the standard deviation and the coefficient of variation ${ }^{2}$ of this series and obtain for the latter the figure 9.5 .

\footnotetext{
2 The formulas for the calculation of these functions are as follows:

$m_{1}=$ a single observation (such as a determination of B.V./Wt.)

$n=$ number of observations

$M=$ arithmetical mean of all observations of the type $m_{1}$

$=\frac{\Sigma m_{1}}{n}$
} 
Bakwin and Rivkin (16), also using the dye method, determined the blood volume of 36 normal infants ranging in age from 12 days to 10 months, and obtained an average ratio of $101 \mathrm{cc}$. per kilogram of body weight. In this series the standard deviation was 14.6 and the coefficient of variation 14 . Plasma volumes averaged $61 \mathrm{cc}$. per kilogram for the same group, and here the coefficient of variation was 12 , indicating a slightly closer correlation than blood volume had shown.

Marriott and Perkins (17) in a study of 7 approximately normal infants under one year of age obtained with the dye method an average figure of 9.1 per cent of the body weight (which may mean $91 \mathrm{cc}$. per kilogram if their figure refers to volume of blood and not mass), with variations from 8.0 to 10.8 per cent. Their individual determinations were not reported.

Darrow, Soule, and Buckman (18) demonstrated a closer agreement between plasma volume and weight than between blood volume and weight. They showed that for any particular age group a practically identical degree of correlation exists between plasma volume per kilogram and plasma volume per square meter of body surface, and further that the part which age plays is expressed in the fact that the expected plasma volume per kilogram rises from an initial level of $50 \mathrm{cc}$. per kilogram shortly after birth (calculated from the observations of authors previously quoted) to a level of abput $62 \mathrm{cc}$. during the first year of life, subsequently falling slowly to a normal level of $50 \mathrm{cc}$. during the fourth year, where it remains through the rest of childhood, or up to 11 years of age which was the upper limit of their study. They found that the ratio plasma volume to body weight varied more widely during the first year of life than later. The curve of variation with age of the ratio plasma volume per square meter of body surface was more complicated, showing a rounded peak at one year followed by a gradual rise throughout childhood; and in general the ratio blood volume per square meter followed a parallel curve.

Standard Deviation $=\sqrt{\frac{\Sigma\left(m_{1}-M\right)^{2}}{n}}$
Coefficient of Variation $=\frac{100 \times \text { Standard Deviation. }}{M}$. 
They calculated the coefficients of variation (referred to by them as the percentage standard deviation) of the ratio plasma volume per kilogram separately for each year of life during the first 11 years and obtained figures ranging from 2 to 8 . Such close agreement as these low coefficients express indicates that in average normal children the

TABLE 7

Twenty-four blood volume and plasma volume determinations in 22 patients

\begin{tabular}{|c|c|c|c|c|c|c|c|c|c|c|}
\hline Patient & 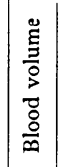 & 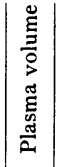 & 造 & 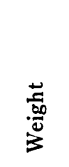 & 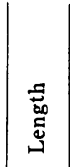 & 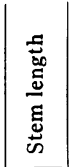 & 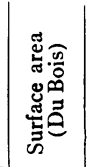 & 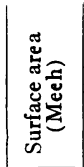 & 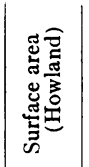 & $\begin{array}{l}\text { Clinical condition for which } \\
\text { patient was admitted }\end{array}$ \\
\hline & $c c$. & $c c$. & mos. & $\mathrm{kgm}$. & $\mathrm{cm}$. & $\mathrm{cm}$. & $s q . \mathrm{cm}$ & $s q . \mathrm{cm}$. & $s q . \mathrm{cm}$. & \\
\hline J. G. . & 220 & 136 & 1 & 2.18 & 51.5 & 33.5 & 1,740 & 2,001 & 1,785 & Congenital syphilis \\
\hline L. S. & 275 & 171 & 12 & 3.53 & 59.5 & 39.5 & 2,375 & 2,759 & 2,435 & Congenital syphilis \\
\hline D. M. & 290 & 190 & 2 & 3.55 & 55.5 & 37.5 & 2,265 & 2,769 & 2,445 & Nutritional disturbance \\
\hline F. B. . & 300 & 198 & 2 & 4.42 & 58.0 & 37.0 & 2,567 & 3,205 & 2,865 & Nutritional disturbance \\
\hline F. T. & 320 & 172 & 5 & 4.58 & 64.0 & 40.5 & 2,800 & 3,282 & 2,942 & Malformation of spine \\
\hline M. A. & 320 & 185 & 6 & 4.81 & 63.0 & 40.0 & 3,100 & 3,390 & 3,053 & Nutritional disturbance \\
\hline J. W. & 340 & 225 & 2 & 4.36 & 57.0 & & 2,520 & 3,175 & 2,836 & Otitis media \\
\hline E. E. & 345 & 209 & 4 & 3.68 & 59.0 & 39.5 & 2,412 & 2,836 & 2,507 & Mongolian idiocy \\
\hline L. G. & 355 & 199 & 9 & 6.38 & 70.0 & 43.5 & 3,440 & 4,093 & 3,811 & Pneumonia \\
\hline C. $\mathrm{K}$. & 370 & 272 & 3 & 3.30 & 54.0 & 35.5 & 2,160 & 2,638 & 2,324 & Prematurity \\
\hline L. H. & 385 & 232 & 5 & 5.20 & & & & 3,571 & 3,241 & Pneumonia \\
\hline S. E. . & 410 & 212 & 5 & 6.72 & 72.5 & 40.3 & 3,610 & 4,238 & 3,976 & Nutritional disturbance \\
\hline D. B. & 440 & 304 & 8 & 6.87 & 65.0 & 40.3 & 3,370 & 4,300 & 4,049 & Pneumonia \\
\hline R. W. & 445 & 315 & 7 & 5.68 & 74.0 & 41.5 & 3,403 & 3,788 & 3,474 & Congenital syphilis \\
\hline W. P. & 455 & 263 & 15 & 6.90 & 75.0 & 47.0 & 3,736 & 4,312 & 4,062 & Congenital cataract \\
\hline J. L & 500 & 270 & 12 & 6.75 & 72.0 & 43.0 & 3,589 & 4,250 & 3,990 & Pneumonia, empyema \\
\hline A. B. & 505 & 219 & 15 & 7.63 & 75.0 & 49.5 & 3,900 & 4,611 & 4,415 & Nutritional disturbance \\
\hline J. P. & 535 & 298 & 13 & 6.35 & & & & 4,080 & $3,7 \overline{9} 7$ & Pertussis, pneumonia \\
\hline M. K. & 550 & 332 & 9 & 5.73 & 67.5 & 45.0 & 3,190 & 3,811 & 3,498 & Pyuria \\
\hline A. $\mathrm{H}$. & 560 & 291 & 23 & 7.58 & 77.0 & & 3,966 & 4,592 & 4,391 & Pertussis, encephalitis \\
\hline M. C.. & 565 & 323 & 11 & 8.27 & 73.0 & & $3,9,50$ & 4,867 & 4,724 & Scarlatina, mastoiditis \\
\hline M. C. & 600 & 337 & 11 & 8.30 & 73.0 & & 3,960 & 4,878 & 4,739 & Scarlatina, mastoiditis \\
\hline A. $\mathrm{H}$. & 620 & 370 & 22 & 7.29 & 77.0 & & 3,900 & 4,473 & 4,251 & Pertussis, encephalitis \\
\hline J. J. & 655 & 367 & 21 & 8.22 & 76.0 & 47. & 4,070 & 4,847 & $4,700 \mid$ & Pertussis, pneumonia \\
\hline
\end{tabular}

body weight is more than a fair index of the total plasma volume as determined by the dye method. It is further suggested by these authors that plasma volume appears to be related primarily to metabolic rate, and that its relations to body weight and surface area are of secondary degree and subject to the same limitations as govern the 
estimation of metabolic rate from measurements of body mass and area.

\section{EXPERIMENTAL RESULTS}

Table 7 presents the results of 24 determinations of blood volume in 22 hospital patients admitted for a variety of causes and who, at the time the determination was made, were not thought to be suffering from any circumstance that would bring about a temporary alteration of blood volume. In other words, the figure obtained for each patient was considered to represent a normal level for that individual at that particular time. Only the age group of the first two years is included. As a measure of the normal blood volume at this age they, of course, suffer the defect of not comprising any strictly normal individuals; yet conversely, by including a variety of nutritional states they are possibly better adapted for showing what correlations are most tenaciously held when the individual deviates widely from the average, and may thus serve to demonstrate, for example, whether body weight or surface area is a measure of total blood volume, even better than would an assembly of entirely normal values.

In comparison of our results with those obtained by others with the dye method, the fundamental differences between the two methods must be borne in mind: first, that the dye method measures the plasma volume directly, while the carbon monoxide method measures the circulating blood volume directly, and secondly, that in the former method the added substance is mixed entirely or mainly in the plasma, whereas in the latter the gas is taken up almost exclusively by the red cells. According to Whipple and his associates (14), these differences are largely responsible for the higher figures which so many observers have obtained in working with the dye method, and in their hands the carbon monoxide method has given in dogs a higher figure than is yielded by the exsanguination method, though it closely approximates the results of the bleeding method where the latter is combined with procedures adapted for including in the total blood volume a figure calculated from the hemoglobin derived from extraction of tissues -in other words, when the non-circulating hemoglobin is included in the total blood volume figure. We do not agree with the statement made by Darrow, Soule, and Buckman (18) that the carbon monoxide method gives results that are lower than the actual blood volume. 
In table 7 we have listed the determined values for blood volume and plasma volume, together with the age, body weight, length, stem length, and body surface as calculated by the three different formulae of Du Bois, Meeh, and Howland (19). The coefficients of correlation (20) in table 8 express the degree of agreement between observations of blood volume or plasma volume and the corresponding measurement of the function under consideration, in the sense that no agreement at all is indicated by a coefficient of 0 , perfect agreement by a coefficient of \pm 1 . For a more detailed discussion of the significance of coefficients of correlation and variation, one is referred to appropriate

TABLE 8

Coefficients of correlation of blood and plasma volume with various body measurements

\begin{tabular}{|c|c|c|}
\hline & Blood volume & Plasma volume \\
\hline Age. & $0.79 \pm 0.08^{*}$ & $0.63^{\circ} \pm 0.12$ \\
\hline Body weight. . & $0.89 \pm 0.05$ & $0.72 \pm 0.11$ \\
\hline Body length.. & $0.86 \pm 0.06$ & $0.68 \pm 0.11$ \\
\hline (Body length) ${ }^{2} \ldots$ & $0.86 \pm 0.06$ & $0.68 \pm 0.11$ \\
\hline (Body length) ${ }^{3}$. & $0.86 \pm 0.06$ & $0.68 \pm 0.11$ \\
\hline Stem length. . & $0.73 \pm 0.11$ & $0.50 \pm 0.18$ \\
\hline (Stem length) ${ }^{2}$. & $0.74 \pm 0.11$ & $0.49 \pm 0.18$ \\
\hline (Stem length) ${ }^{3}$. & $0.73 \pm 0.11$ & $0.48 \pm 0.19$ \\
\hline Surface area (Du Bois formula). & $0.89 \pm 0.05$ & $0.71 \pm 0.11$ \\
\hline Surface area (Meeh-Rubner-Heubner formula) & $0.87 \pm 0.05$ & $0.72 \pm 0.10$ \\
\hline Surface area (Howland formula)...... & $0.88 \pm 0.05$ & $0.73 \pm 0.10$ \\
\hline
\end{tabular}

* The second figure in each column represents the standard error of the coefficient $r$, obtained from the formula $e(r)=\frac{1-r^{2}}{\sqrt{n}}$.

treatises on the theory of statistics; in general, however, there is a parallelism in the degree with which the former approaches \pm 1 and the latter approaches 0 when correlation of the two variables is treated by the two methods.

The coefficients of correlation listed in table 8 show that the linear correlation is best between blood volume and body weight, blood volume and surface area, and blood volume and body length. On the other hand plasma volume shows poor agreement with any of these measurements. If the blood volumes are plotted as ordinates against the body weight as abscissae, points representing individual 
TABLE 9

Ratio of blood volume to various body measurements

\begin{tabular}{|c|c|c|c|c|c|}
\hline Patient & 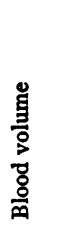 & 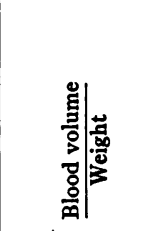 & 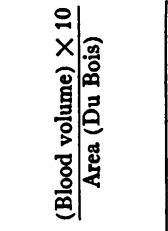 & 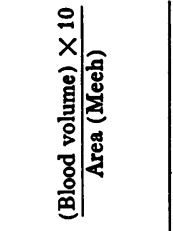 & 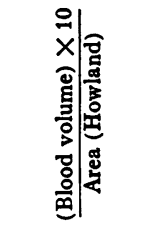 \\
\hline & $c c$. & & & & \\
\hline J. G............ & 220 & 100.9 & 1.264 & 1.099 & 1.233 \\
\hline L. S.... & 275 & 77.9 & 1.159 & 0.997 & 1.179 \\
\hline D. M....... & 290 & 81.7 & 1.280 & 1.047 & 1.186 \\
\hline F. B......... & 300 & 67.9 & 1.169 & 0.936 & 1.047 \\
\hline F. T......... & 320 & 69.9 & 1.143 & 0.975 & 1.087 \\
\hline M. A............ & 320 & 66.5 & 1.032 & 0.944 & 1.048 \\
\hline J. W...... & 340 & 78.0 & 1.349 & 1.071 & 1.199 \\
\hline E. E........... & 345 & 93.2 & 1.431 & 1.216 & 1.376 \\
\hline L. G............ & 355 & 55.6 & 1.032 & 0.867 & 0.931 \\
\hline C. $K \ldots \ldots \ldots \ldots \ldots$ & 370 & 112.1 & 1.713 & 1.403 & 1.592 \\
\hline L. H...... & 385 & 74.0 & & 1.079 & 1.188 \\
\hline S. E. $\ldots \ldots \ldots \ldots \ldots$ & 410 & 61.0 & 1.136 & 0.967 & 1.031 \\
\hline D. B............. & 440 & 64.1 & 1.306 & 1.024 & 1.086 \\
\hline R. W............ & 445 & 78.3 & 1.307 & 1.175 & 1.280 \\
\hline W. P........... & 455 & 66.0 & 1.218 & 1.055 & 1.120 \\
\hline J. L.... & 500 & 74.1 & 1.393 & 1.176 & 1.253 \\
\hline A. B....... & 505 & 66.2 & 1.295 & 1.095 & 1.144 \\
\hline J. P..... & 535 & 84.3 & & 1.311 & 1.409 \\
\hline M. K............. & 550 & 96.0 & 1.725 & 1.444 & 1.571 \\
\hline A. $H \ldots \ldots \ldots \ldots \ldots$ & 560 & 73.9 & 1.412 & 1.220 & 1.275 \\
\hline M. C.............. & 565 & 68.4 & 1.430 & 1.161 & 1.196 \\
\hline M. C. ........... & 600 & 72.3 & 1.515 & 1.230 & 1.266 \\
\hline A. H.... & 620 & 85.0 & 1.590 & 1.386 & 1.459 \\
\hline J. J.......... & 655 & 79.6 & 1.609 & 1.351 & 1.393 \\
\hline Number of Observations & & 24 & 22 & 24 & 24 \\
\hline Arithmetical Mean. & & $77.0 \pm 2.6^{*}$ & $1.34 \pm 0.04$ & $1.14 \pm 0.03$ & $1.23 \pm 0.03$ \\
\hline Standard Deviation.. & & $13.0 \pm 1.9$ & $0.20 \pm 0.03$ & $0.16 \pm 0.02$ & $0.17 \pm 0.02$ \\
\hline Coefficient of Variation. & & $17 \pm 2$ & $15 \pm 2$ & $14 \pm 2$ & $14 \pm 2$ \\
\hline
\end{tabular}

* The second figure gives the standard error.

determinations will lie on both sides of a straight line the equation for which is obtained from the coefficient and is expressed by the for- 
mula B.V. $=61 \mathrm{Wt} .+80$. A simpler formula, and one which for this series gives an approximation almost equally satisfactory, is obtained from the average of the ratios of blood volume to weight, as expressed in table 9 , and is represented by B.V. $=77 \mathrm{cc}$. per kilogram.

From a study of these values, it appears that body weight or surface area calculated by any one of the three formulas used gives a fairly close measure of blood volume even in the presence of such sharp deviations of these functions from the values expected on the basis of age as are offered in this group of patients. For these ratios we have tabulated the values in individual observations (table 9) and have calculated the average figures, standard deviations, and coefficients of variation, with their standard errors. Since the correlation of blood volume with surface area is not significantly closer than that of blood volume with body weight, there is no material advantage in stating the formula for obtaining the blood volume from surface measurement, since the latter is readily obtainable only by the use of other formulas such as those quoted, based on weight or weight-and-length measurements.

While the multiplication of determinations may conceivably reduce these standard deviations and increase the accuracy of prediction of the figure for the total blood volume, it is equally likely that there will always remain a number of individuals who, by reason of a constitutional factor not sufficiently taken into account in formulas of this simplicity, will show values deviating more or less sharply from such limits. Our reasons for believing this to be true are based on the fact that we obtained duplicate determinations of blood volume in the case of two patients, L. G. and M. K., whose points on the plotted graph of blood volume per kilogram were located at a greater distance from the line of the regression equation B.V. $=61 \mathrm{Wt} .+80-$ the one above, the other below it - than any other points in the scatter. For L. G. we obtained the value $355 \mathrm{cc}$. on admission, $355 \mathrm{cc}$. 11 days later; for M. K., $485 \mathrm{cc}$. on admission, $550 \mathrm{cc} .17$ days later. The first values in each case have not been included in the determinations subjected to analysis in this paper for the reason that at the time they were obtained both patients showed some clinical evidence of dehydration and it was thought that they might at the time be suffering a temporary disturbance in blood volume. However, while they are justly 
excluded from the set of "normal values" they still serve effectively to corroborate the second set of figures and eliminate the likelihood of gross technical error in their determination.

Our results differ, then, from those previously reported by other authors mainly in three ways: our average values for blood volume per kilogram are considerably lower; the correlation between blood volume and various simple body measurements is closer than between plasma volume and those measurements; and finally, the scattering of our ratio values of blood volume per kilogram is considerably greater than that obtained particularly by Darrow, Soule, and Buckman (18). The first point of difference may be ascribed to our use of the carbon monoxide method as contrasted with their use of the dye method. When the measurement of the circulating blood volume depends on the quantitative administration of a foreign substance the loss of which from circulation, whether it be by diffusion out of the vascular system or by dilution in reservoirs of plasma in the small vessels as claimed by Whipple (14), would result in a raising of the analytical figure, it is difficult to see how our results can be too low. They may be too high, if muscle hemoglobin binds any considerable share of the respired carbon monoxide. The second point of difference rests also on the choice of method; since the carbon monoxide method determines the blood volume directly, it is independent of additional error from hematocrit readings. Finally, the wider scattering of our results may in all probability be ascribed to the variety of developmental and nutritional states represented in our series.

\section{SUMMARY}

1. A technique is described for the determination in infants of the circulating blood volume by the carbon monoxide method, based on the successful use of this method in tests on adults.

2. In comparison with the dye method, the carbon monoxide method gave results which were more uniform and showed a fair conformity with body weight.

3. In a small series of determinations of blood volume in patients less than two years of age, the correlation of blood volume to body weight, to surface area, and to body length suggested a normal interrelationship of these measurements. 
4. As an estimate of the circulating blood volume in infants, exclusive of the new-born group, the formula

Blood Volume in cc. $=($ Body Weight in $\mathrm{kgm}) \times.(77 \pm 13)$

may be expected to give the correct figure in more than half the cases.

\section{BIBLIOGRAPHY}

(1) Müller, E., Jahrb. f. Kinderh. 1910, lxxii, 176. Die Blut-und Hämoglobinmenge und die Sauerstoffkapazität des Blutes bei gesund- und bei blassaussehender. Kindern.

(2) Zuntz, N., and Plesch, J., Biochem. Ztschr. 1908, xi, 47. Methode zur Bestimmung der zirkulierenden Blutmenge beim lebenden Tiere.

(3) Gréhant, N. and Quinquaud, E., J. de l'anat. et de la physiol. 1882-83, xviii, 564. Mesure de la Quantité de Sang contenu dans l'organisme d'un Mammifère Vivant. Id.: Compt. rend. Acad. Sci., 1882, xciv, 1450. Mesure du volume de sang contenu dans l'organisme d'un Mammifère Vivant.

(4) Haldane, J., and Smith, J. L., J. Physiol., 1899-1900, xxv, 331. The Mass and Oxygen Capacity of the Blood in Man.

(5) Douglas, C. G., J. Physiol, 1905, xxxiii, 493. A Method for the Determination of the Volume of Blood in Animals. J. Physiol., 1910, xl, 472. The Determination of the Total Oxygen Capacity and Blood Volume at Different Altitudes by the Carbon Monoxide Method.

(6) Salvesen, H. A., J. Biol. Chem. 1919, xl, 109. The Determination of Blood Volume by the Carbon Monoxide Method.

(7) Chang, H. C., and Harrop, G. A., Jr., J. Clin. Invest., 1928, v, 393. The Determination of the Circulating Blood Volume with Carbon Monoxide.

(8) Van Slyke, D. D., and Robscheit-Robbins, Frieda S., J. Biol. Chem., 1927, lxxii, 39. The Gasometric Determination of Small Amounts of Carbon Monoxide in Blood, and Its Application to Blood Volume Studies.

(9) Harington, C. R., and Van Slyke, D. D., J. Biol. Chem., 1924, lxi, 575 . On the Determination of Gases in Blood and Other Solutions by Vacuum Extraction and Manometric Measurement. II.

(10) Van Slyke, D. D., and Neill, J. M., J. Biol. Chem., 1924, lxi, 523. The Determination of Gases in Blood and Other Solutions by Vacuum Extraction and Manometric Measurement. I.

(11) Stadie, W. C., and Martin, K. A., J. Clin. Invest., 1925, ii, 77. The Elimination of Carbon Monoxide from the Blood.

(12) Arnold, H. R., Carrier, E. B., Smith, H. P., and Whipple, G. H., Am. J. Physiol., 1921, lvi, 313. Blood Volume Studies. V. The Carbon Monoxide Method-Its Accuracy and Limitations.

(13) Keith, N. M., Rowntree, L. G., and Geraghty, J. T. Arch. Int. Med., 1915, xvi, 547. A Method for the Determination of Plasma and Blood Volume. 
(14) Smith, H. P., Arnold, H. R., and Whipple, G. H., Am. J. Physiol., 1921, lvi, 336. Blood Volume Studies. VII. Comparative Values of Welcker, Carbon Monoxide, and Dye Methods for Blood Volume Determinations. Accurate Estimation of Absolute Blood Volume.

(15) Lucas, W. P., and Dearing, B. F., Am. J. Dis. Child., 1920, xxi, 96. Blood Volume in Infants Estimated by the Vital Dye Method.

(16) Bakwin, H., and Rivkin, Helen, Am. J. Dis. Child., 1924, xxvii, 340. The Estimation of the Volume of Blood in Normal Infants and in Infants with Severe Malnutrition.

(17) Marriott, W. M., and Perkins, J. F., quoted in Marriott, W. M., Am. J. Dis. Child., 1920, xx, 461. Some Phases of the Pathology of Nutrition in Infancy.

(18) Darrow, D. C., Soule, H. C., and Buckman, T. E., J. Clin. Invest., 1928, $\mathrm{v}, 243$. Blood Volume in Normal Infants and Children.

(19) Area in sq. cm. $=(\text { Wt. in } \mathrm{kgm} \text {. })^{0.425} \times(\text { Height in } \mathrm{cm} .)^{0.725} \times 71.84$. Du Bois, D., and Du Bois, E. F., Arch. Int. Med., 1916, xvii, 863. Clinical Calorimetry. X. A Formula to Estimate the Approximate Surface Area If Height and Weight be Known.

Area in sq. $\mathrm{cm} .=(\text { Weight in grams })^{\frac{3}{2}} \times 11.9$. The formula of Meeh and the coefficient of Rubner and Heubner are quoted by Benedict, F. G., and Talbot, F. B. The gaseous Metabolism of Infants. Carnegie Institute of Washington, 1914.

Area in sq. cm. $=0.483$ (Weight in grams) +730 . Quoted by Benedict and Talbot.

(20) Yule, G. U., An Introduction to the Theory of Statistics. London, Charles Griffin and Co., 1927, 8th Edition. 